\title{
Empowering adolescent girls in rural Bangladesh: Kishori Abhijan
}

\section{Sajeda Amin}

Population Council

Follow this and additional works at: https://knowledgecommons.popcouncil.org/departments_sbsr-pgy

Part of the Demography, Population, and Ecology Commons, Family, Life Course, and Society Commons, Gender and Sexuality Commons, and the International Public Health Commons How does access to this work benefit you? Let us know!

\section{Recommended Citation}

Amin, Sajeda. 2011. "Empowering adolescent girls in rural Bangladesh: Kishori Abhijan," Promoting Healthy, Safe, and Productive Transitions to Adulthood Brief no. 13. New York: Population Council. 


\title{
Empowering adolescent girls in rural Bangladesh: Kishori Abhijan
}

\author{
Prepared by Sajeda Amin
}

G irls and women in Bangladesh have benefited from rapid social change in the past two decades. Girls surpassed boys in primary-school completion in the 1990s, fertility levels were halved from six births per woman to fewer than three, and one-third of married women belonged to self-help and credit groups. Yet despite this progress, the majority of adolescent girls in Bangladesh still find their lives constrained by the custom of early marriage. According to recent research, 68 percent of women aged 20-24 were married before the legal minimum age of 18 (Amin et al. 2006). Married adolescent girls were socially isolated, they had fewer friends and reported feeling vulnerable, and they had little knowledge of health risks and sexuality.

\section{"Adolescent Girls' Adventure" introduces livelihoods opportunities}

In 2001, UNICEF initiated a pilot intervention to test whether livelihoods opportunities could ameliorate the situation of early marriage and other adverse outcomes for girls in rural Bangladesh. "Kishori Abhijan" (Adolescent Girls' Adventure) aimed to lower school dropout rates, increase girls' independent economic activity, and raise the age at which girls marry. Life-skills training consisted of enhancing self-esteem and leadership skills and providing education related to gender roles and discrimination, health and nutrition, and legislation and legal rights, particularly early marriage and girls' and women's rights. Livelihoods training included specific vocational skills such as poultry care, handicrafts, sewing, photography, and teacher training.

The intervention, conducted over three years in 14 rural districts, was a joint effort of UNICEF, the United Nations Population Fund (UNFPA), the Bangladesh Institute of Development Studies (BIDS), the Bangladesh Rural Advancement Committee (BRAC), and the Centre for Mass Education in Science (CMES). The two local nongovernmental

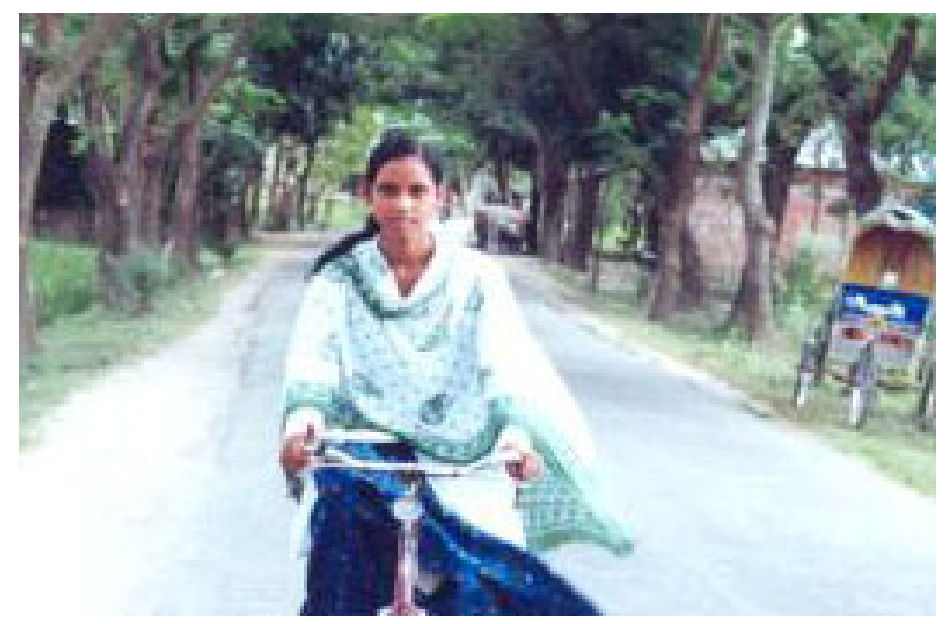

A program leader rides a bicycle to visit Kishori Abhijan participants in farflung villages.

organizations, BRAC and CMES, implemented the intervention, enrolling 15,000 girls. The Population Council, in collaboration with BIDS, evaluated the intervention, focusing on three of the 14 districts to represent a range of initial conditions in terms of poverty, early marriage, and schooling.

In 2001 researchers conducted a baseline survey in 75 intervention and 15 control villages with 6,000 randomly selected married and unmarried boys and girls between ages 13 and 22 . A subset of 2,500 girls was successfully reinterviewed in 2003 during a follow-up survey. Three villages were chosen randomly for an in-depth prospective qualitative study.

The baseline survey documented important achievements in rural Bangladesh in educational attainment and health awareness, but it also highlighted areas in need of concerted policy efforts; in particular, 
the paucity of livelihood opportunities and the detrimental social consequences of early marriage and childbearing among adolescent girls. Large differences were found among the three study districts in the pattern of marriage, demands for dowry at marriage, reproductive health, and schooling of girls. Married adolescent girls were socially isolated and knew little about health risks and sexuality. Reports of physical abuse were high among all adolescents, regardless of sex or marital status. On a positive note, the survey highlighted the important role that economic incentive schemes have played in retaining poor children-especially adolescent girls -in school in all three districts. A much narrower gender gap was observed in the schooling of younger girls and boys compared with older adolescents, although girls at all socioeconomic levels still drop out of school when they marry. Dowry remained an important factor in all three districts, but especially among the wealthiest households and in more prosperous communities (Amin et al. 2002).

\section{Analyzing program effects}

Delayed marriage

Whereas many evaluations estimate the effects of a particular project by comparing participants to nonparticipants, Council researchers took a different approach. After comparing project participants with adolescent girls who did not participate, they realized that these two groups differed in substantial ways. Participants were usually younger and less likely to be married and had spent more time in school. To account for these differences, researchers matched program participants with nonparticipants who had identical or very similar characteristics. Of the 445 participants included in the survey, 360 were matched with other adolescents in the same districts (Amin and Suran 2005a).

Although most project participants delayed marriage longer than did their matched counterparts who did not participate, these findings were not statistically significant. This result, however, changed when researchers distinguished between matched and unmatched participants. Whereas matched participants did not delay marriage, unmatched participants waited significantly longer to marry. Figure 1 shows the relative odds for adolescent girls of being married, calculated from hazard ratios obtained after modeling the duration to marriage.

Compared with matched nonparticipants, only unmatched participants exhibited decreased odds of being married. The unmatched participants were relatively young girls attending school at grade levels appropriate for their age and living in the poorest district in the sample.

\section{Delayed marriage . . . at a price?}

As noted above, dowry was an important factor in all three districts. Respondents (both participants and nonparticipants) who married at later ages often paid higher dowries to their husband's family. Figure 2 shows the mean dowry paid by respondents who married in the interim between the two surveys. Dowries increased in tandem with age at marriage. Other projects aiming to delay marriage in areas where dowries
Figure 1. Relative odds of marriage among participants and their matched counterparts

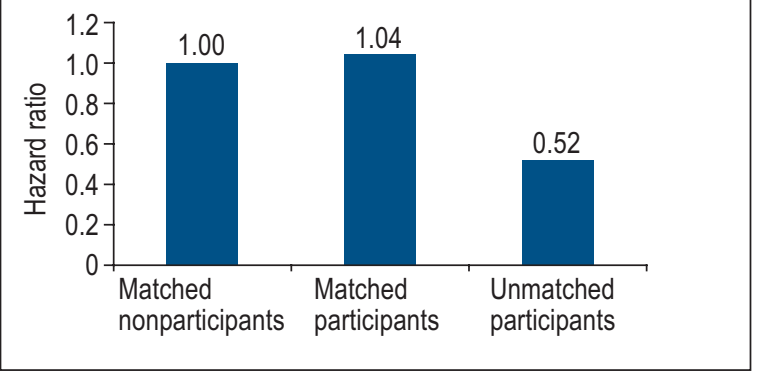

Figure 2. Mean dowry payment by age at marriage among respondents married between 2001 and 2003

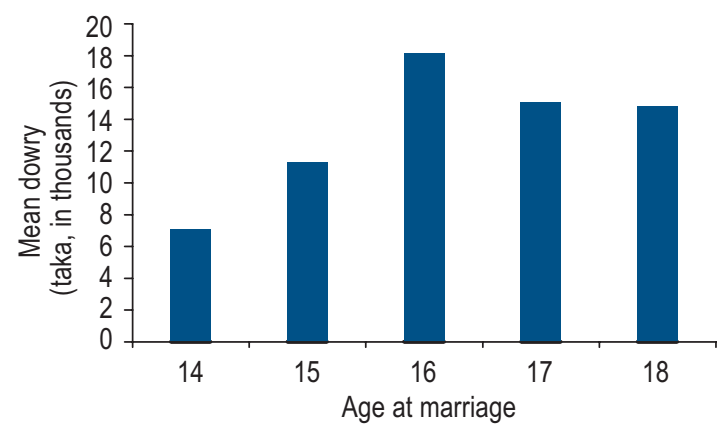

Note: To ensure that the number of respondents in each category exceeded 30 , the age at marriage is shown for girls between 14 and 18 years of age only.

are paid should take into account the relationship between marriage payments and girls' age, especially among girls from poorer families. With fewer economic resources, such girls are less able to afford the increased dowry payments that accompany delayed marriage.

\section{Working for cash}

Kishori Abhijan increased both the number of girls working for cash and the amount of income they earned. These outcomes were most pronounced in programs that included microcredit. Despite concerns about conflicts between work and schooling, cash work did not lead to school dropout. Girls who reported working for cash usually spent fewer hours on schoolwork outside the classroom, however. This result may well reflect the fact that decisions about school and work are made simultaneously. If girls work only during days of the week when school is not in session, no discernible impact of work on schooling may result.

\section{Schooling}

Girls in rural Bangladesh usually continue to attend secondary school until they marry, and their participation in Kishori Abhijan had no significant effect on school dropout rates. Rates of dropout from the project were more closely tied to marriage than to education. Although the project did not specifically exclude married girls, most girls were unable 
to continue to participate after marriage because being married usually entails migration to the husband's village and it places increased restrictions on girls' mobility.

\section{Increased health knowledge}

Population Council investigators documented substantive improvements in specific knowledge about health and disease among project participants relative to nonparticipants. Participants were more likely to give accurate answers to questions about transmission of HIV and about aspects of female reproductive biology.

\section{Reduced social isolation}

Researchers also found that Kishori Abhijan participants had formed a stronger sense of self-worth and connectedness. Participants were more likely to report having friends in the same village and more likely to have traveled outside the village, gone to the movies, visited friends in the village, listened to the radio, watched television, and read the newspaper. Many of these behaviors also changed for nonparticipants, and differences between the two groups of adolescents were not statistically significant. Thus, Kishori Abhijan's effectiveness in reducing social isolation among both participants and nonparticipants may be one way in which the project's influence diffused widely throughout the rural districts.

\section{Goals of Kishori Abhijan}

The leaders of Kishori Abhijan set out several goals (Amin, Mahmud, and Huq 2002):

- to increase by at least two years the median age at marriage of girls in the project;

- to increase by at least 30 percent the independent economic activity of girls aged $15-18$ years;

- to increase by at least 30 percent girls' rates of enrollment and retention in primary and secondary schools;

- to increase by 20 percent the primary-school completion rate of adolescent girls; and

- to increase the visibility of adolescent girls as a special-interest group in the media and in national programs and policies.

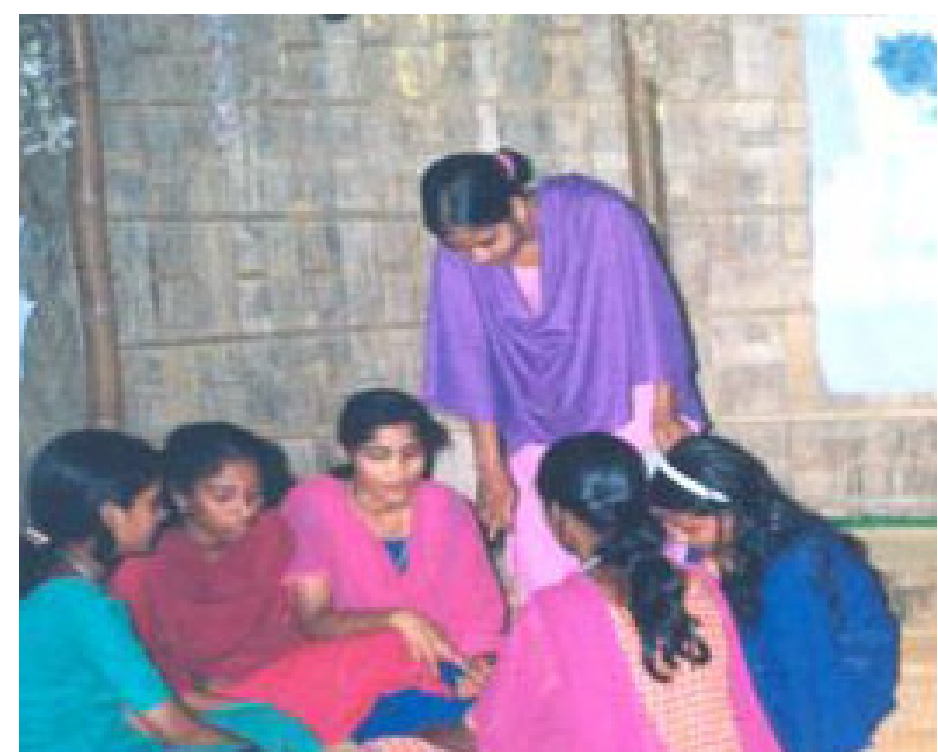

Girls participating in Kishori Abhijan met weekly to learn valuable life skills and receive livelihoods training.

\section{Lessons learned}

The program significantly increased self-employment and part-time employment opportunities for participating girls of all ages. All participants demonstrated increased knowledge about health, family planning, nutrition, and the causes of disease. They enjoyed greater mobility, as measured by reported activities such as meeting friends, visiting neighbors, and moving about autonomously in the village. For younger girls (aged 12-14) in the poorest district, the program contributed to improved school-enrollment rates and lower marriage rates (Amin and Suran 2005a); however, girls' schooling continues to be compromised because of early marriage and poverty (Mahmud and Amin 2006).

No substantial differences were observed in outcomes between the different programs run by the two NGOs-BRAC and CMES-suggesting that targeting programs to poor rural girls makes a difference, even if styles of implementation differ.

The response of community members to these programs suggests their readiness for change. Unfortunately, neither program incorporated a specific emphasis on dowry; rural households continued to be impoverished and expressed frustration with the escalation of dowry costs. Yet data from our study showed clearly that dowry does little to improve the lives of girls. Infant girls who paid no dowry were less likely to suffer physical abuse (Amin et al. 2004; Amin and Suran 2005b) than those paying dowry.

The program evaluation suggests that future programs to delay marriage should focus on younger adolescents (aged 12-14) in the poorest families and districts of rural Bangladesh. Because of the persistent and pernicious nature of dowry demands, any effort to delay marriage must also address issues related to marriage transactions. 


\section{Expanding the project to reach more girls}

The life-skills component of Kishori Abhijan has been scaled up to enroll more than 250,000 girls in 58 districts (http://www.brac. net/content/adolescent-development-programme). An adolescent microcredit initiative funded entirely by BRAC functions as a separate program and covers over 400,000 young women. BRAC has also implemented variants of its adolescent program in Southern Sudan, Tanzania, and Uganda (Islam et al. 2009). To incorporate financial literacy components into these programs, the Population Council has recently piloted a 20 -hour financial education program that has shown promising results (http://www.popcouncil.org/projects/307_PromoteFinancialEd.asp). The involvement of the first generation of Kishori Abhijan members as program implementers and mentors in the financial education programs attests to the sustainable and long-term impact of early investments in adolescents.

In a 2008 UNICEF evaluation of child protection interventions, Kishori Abhijan was the third most highly rated intervention for evidence quality, receiving excellent scores on all evaluative measures (UNICEF 2008). The purpose of the evaluation was to gather an authoritative evidence base, indexing best practices in facilitating systemic changes in child protection.

\section{References and related publications}

Amin, Sajeda and Luciana Suran. 2005a. "Program efforts to delay marriage through improved opportunities: Some evidence from rural Bangladesh." Paper presented at the Annual Meeting of the Population Association of America, Philadelphia, 31 March-2 April.

Amin, Sajeda and Luciana Suran. 2005b. "The impact of marriage payments on leisure, housework and abuse of young wives: Some evidence from rural Bangladesh." Paper presented at the Annual Meeting of the Population Association of America, Philadelphia, 31 March-2 April.

Amin, Sajeda, Simeen Mahmud, and Lopita Huq. 2002. "Rural adolescents in Bangladesh, 2001: A report drawn from the baseline survey for the
Bangladesh adolescent girls' livelihood Kishori Abhijan project." Dhaka: UNICEF.

Amin, Sajeda, Nasheeba Selim, and Nashid Kamal Waiz. 2006. "Causes and consequences of early marriage in Bangladesh." Background report for workshop on programs and policies to prevent early marriage. Dhaka: Population Council.

Amin, Sajeda, Luciana Suran, Lopita Huq, and Kobita Chowdhury. 2004. "Does Dowry Make Life Better for Brides? A Test of Bequest Theories of Dowry." Population Council Research Division Working Paper 195. New York: Population Council.

Islam, A., A. Zerihun, \& S. Ramdoss. 2009. Scaling adolescent empowerment programs: The BRAC experience in Africa. URL: http://www.youthenterpriseconference.org/agenda.asp

Mahmud, Simeen and Sajeda Amin. 2006. "Girls' schooling and marriage in rural Bangladesh," in Emily Hannum and Bruce Fuller (eds.). Children's Lives and Schooling Across Societies, Research in Sociology of Education. New York: Elsevier JAI, Volume 15.

United Nations Children's Fund. 2008. UNICEF Child Protection Meta-Evaluation. http://www.unicef.org/protection/index.html

\section{Donors}

Department for International Development (DFID), Hewlett Foundation, The Andrew W. Mellon Foundation, The Rockefeller Foundation, United Nations Children's Fund (UNICEF), United States Agency for International Development (USAID)

\section{Partner institutions}

Bangladesh Rural Advancement Committee (BRAC)

Centre for Mass Education in Science (CMES)

Women's Directorate, Government of Bangladesh

\section{Research collaborators}

Simeen Mahmud and Lopita Huq, Bangladesh Institute of Development Studies (BIDS)

\section{Population Council}

The Population Council changes the way the world thinks about critical health and development issues. We seek to understand the causes and consequences of gender inequality and the disparities in opportunity that arise during adolescence. We provide the evidence for better on-theground programs and policies that ensure successful and productive transitions to adulthood in developing countries. www.popcouncil.org

(c) 2011 The Population Council, Inc. 